\title{
Alterações cutâneas com ziprasidona
}

\section{Drug Eruptions Associated with Ziprasidone}

\author{
Luciana Porto Cavalcante \\ DA NÓBREgA ${ }^{1}$ \\ LEONARDO BALDAÇARA ${ }^{1}$ \\ FABIANE KUMAGAI ${ }^{1}$ \\ ANDREA FREIRIAS ${ }^{1}$ \\ SÉrgio TAMAI ${ }^{1}$ \\ Marsal SANCHES ${ }^{1}$
}

\begin{abstract}
Resumo
Os antipsicóticos podem estar associados a alterações cutâneas adversas. Relatamos o caso de uma paciente do sexo feminino, 47 anos, em acompanhamento ambulatorial com o diagnóstico de esquizofrenia. Estava em uso de ziprasidona há sete semanas. Prescrita inicialmente na dose de 80 $\mathrm{mg}$ ao dia, a medicação foi aumentada para $120 \mathrm{mg}$ após seis semanas. Sete dias após o aumento da dose, a paciente apresentou quadro de prurido associado a lesões eritematosas em alvo, acometendo tronco, membros superiores e inferiores. Após a suspensão do antipsicótico, houve remissão do quadro dermatológico. Embora haja menção prévia a efeitos colaterais de natureza cutânea durante o uso desta medicação, não encontrou-se na literatura relatos de associação entre eritema multiforme e ziprasidona.
\end{abstract}

Palavras-chave: Antipsicótico, dermatopatia, eritema multiforme, erupção por droga, ziprasidona.

\begin{abstract}
There are descriptions of skin reactions secondary to antipsychotic use. We reported a case of erythema multiform associated with ziprasidone use in a 47-year-old female patient diagnosed with schizophrenia. The patient was receiving the medication ( $80 \mathrm{mg} /$ day) for seven weeks, and the dose was increased to $120 \mathrm{mg} /$ day. Seven days after the dose change, the patient presented pruritus and erythematosus lesions in trunk, upper and lower members. The medication was discontinued and there was a complete improvement of the lesions. We were unable to find previous reports of association between erythema multiform and ziprasidone.
\end{abstract}

Key words: Antipsychotics, dermatopatia, drug eruptions, erythema multiform, ziprasidone. 


\section{Introdução}

Os antipsicóticos são empregados no manejo de uma ampla gama de transtornos mentais, estando especialmente indicados no tratamento da esquizofrenia. Embora classicamente seus efeitos colaterais mais comuns estejam relacionados a alterações extrapiramidais, é fato que manifestações sistêmicas podem estar associadas ao seu uso. É o caso das afecções cutâneas adversas, apresentadas por até $5 \%$ dos pacientes recebendo medicação antipsicótica (Warnock e Morris, 2002). Dentre estas alterações estão incluídos prurido, urticária, fotossensibilidade, erupções exantematosas, alopécia, eritema fixo e, raramente, eritema multiforme (Tabela 1).

A ziprasidona é um antipsicótico atípico recentemente introduzido no mercado. Este trabalho relata um caso de lesões cutâneas sugestivas de eritema multiforme minor associado ao uso desta medicação.

\section{Relato de caso}

Uma paciente do sexo feminino, 47 anos, em acompanhamento ambulatorial com diagnóstico de esquizofrenia, apresentava tempo de evolução da doença de nove anos, sendo que nos últimos meses vinha evoluindo com piora progressiva de seu quadro psiquiátrico, especialmente de sua sintomatologia negativa. Vinha recebendo haloperidol $5 \mathrm{mg}$ ao dia, por via oral, já há cinco meses. Foi então optada pela substituição de sua medicação por ziprasidona. Prescrita inicialmente na dose de $80 \mathrm{mg}$ ao dia, a medicação foi aumentada para $120 \mathrm{mg}$ após seis semanas. Sete dias depois do aumento da dose, a paciente apresentou quadro de prurido, de início súbito, associado a lesões eritematosas em alvo (Figuras 1 e 2). Tais lesões acometeram inicialmente o tronco, progredindo após o quarto dia do início dos sintomas para membros superiores e após o quinto dia para membros inferiores. Os exames laboratoriais, tais como hemograma, plaquetas, transaminases, fator antinúcleo, fator reumatóide e sorologias para hepatite, HIV e VDRL foram negativos. A velocidade de hemossedimentação foi igual a $25 \mathrm{~mm}$ na primeira hora. Após a suspensão do antipsicótico, houve remissão espontânea do quadro clínico em quatro dias.

A paciente não vinha utilizando quaisquer outros medicamentos à época do surgimento das lesões cutâneas. Além disso, não apresentava histórico de afecções cutâneas de qualquer natureza anteriormente ao uso da ziprasidona. Após a suspensão da droga, passou a receber olanzapina $5 \mathrm{mg}$ ao dia, sem que alterações cutâneas semelhantes às descritas tenham sido observadas ao longo de sete meses de seguimento ambulatorial.

\section{Discussão}

Apesar da maioria das reações cutâneas secundárias ao uso de antipsicóticos ser de natureza benigna,

Tabela 1. Tipos de alterações dermatológicas associadas ao uso de antipsicóticos.*

\begin{tabular}{ll}
\hline Alteração & Drogas associadas \\
\hline Prurido & Fenotiazida, risperidona, clozapina, quetiapina, olanzapina, tiotixeno \\
\hline Reações exantematosas & $\begin{array}{l}\text { Fenotiazida, ziprasidona, clozapina, tiotixeno, haloperidol, risperidona, quetiapina, } \\
\text { pimozida, olanzapina }\end{array}$ \\
\hline Urticária & Fenotiazida, ziprasidona, clozapina, olanzapina, risperidona \\
\hline Eritema fixo & Clorpromazina, risperidona, haloperidol, quetiapina, olanzapina \\
\hline Fotossensibilidade & Fenotiazida, ziprasidona, clozapina, haloperidol, risperidona, olanzapina, quetiapina \\
\hline Pigmentação induzida por drogas & Fenotiazida, risperidona, clozapina, quetiapina, haloperidol, olanzapina \\
\hline Alopécia & Haloperidol, ziprasidona, olanzapina, risperidona \\
\hline Acne & Haloperidol, quetiapina \\
\hline Reação psoriaseforme & Ouetiapina, risperidona \\
\hline Erupções seborreicas & Fenotiazida, quetiapina, olanzapina \\
\hline Hiper-hidrose & Olanzapina, risperidona, pimozida, quetiapina \\
\hline Eritema multiforme & Clozapina, risperidona. \\
\hline Síndrome de Stevens-Johnsons & Clozapina, clorpromazina. \\
\hline Reação de hipersensibilidade & Olanzapina \\
\hline Vasculite & Clozapina \\
\hline Dermatite esfoliativa & Fenotiazida, risperidona, quetiapina, ziprasidona \\
\hline
\end{tabular}




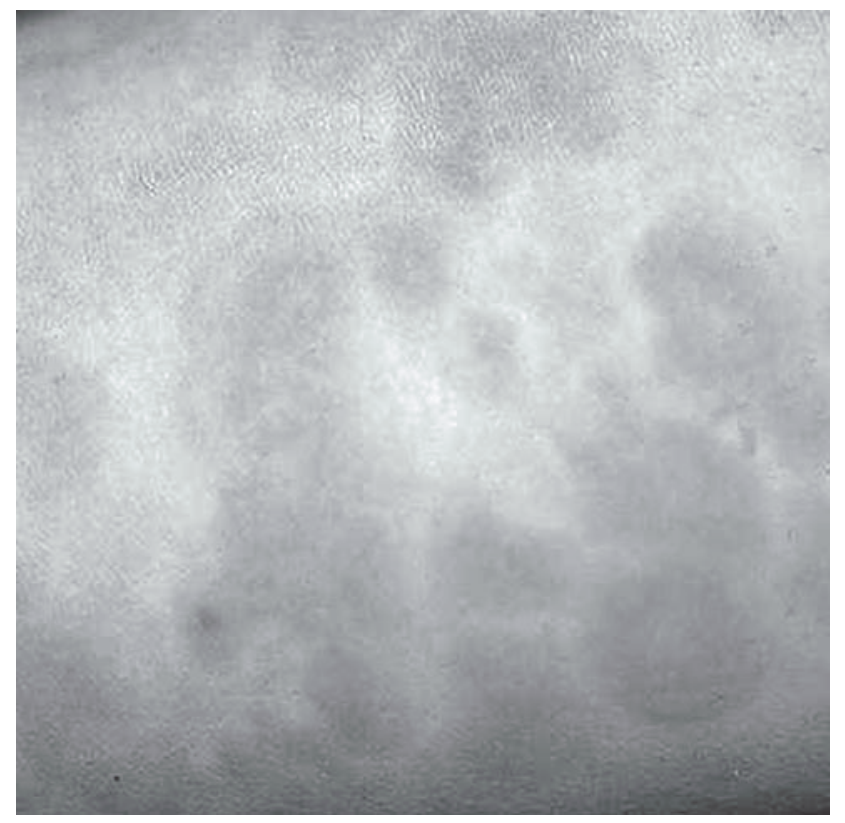

Figura 1. Lesões cutâneas em alvo, localizadas em tronco. Apresentadas por paciente em uso de ziprasidona.

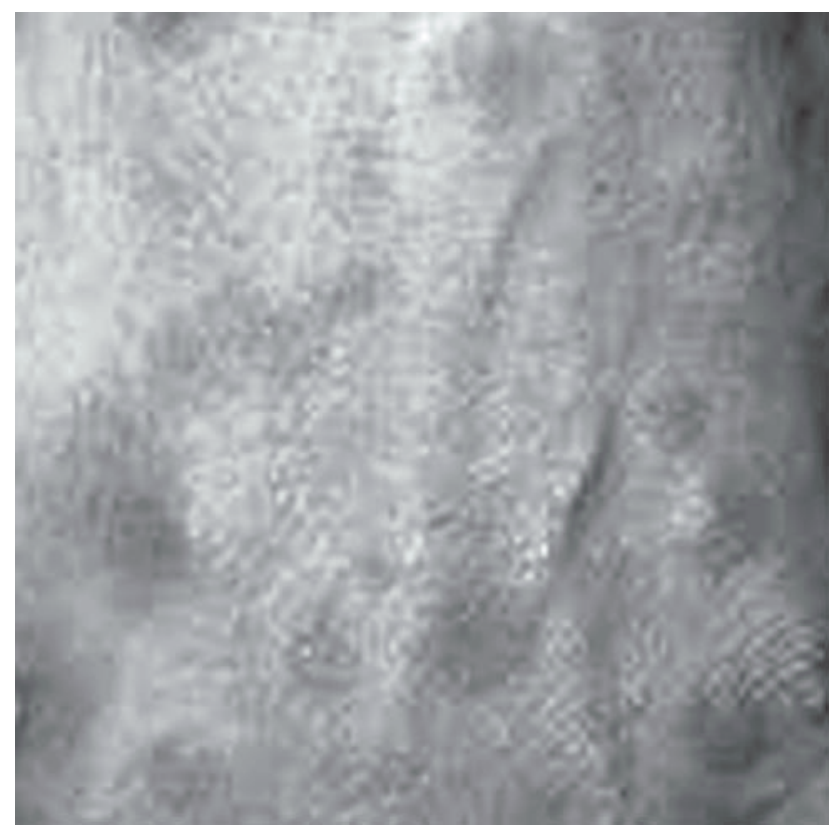

Figura 2. Lesões cutâneas em alvo, logalizadas em região palmar. Apresentadas por paciente em uso de ziprasidona. reações graves, tais como o eritema multiforme, são passíveis de ocorrência (Warnock e Morris, 2002).

O eritema multiforme é uma reação clínica e histológica mucocutânea aguda que pode ser deflagrada por diversos fatores, principalmente infecções e drogas (Brett et al., 2001). Trata-se de um quadro potencialmente grave que pode estar associado a considerável mortalidade, principalmente na forma major (Brett et al., 2001). As características clínicas que sugerem maior severidade são: febre alta, linfoadenopatia, eritema confluente, edema facial, bolhas, dispnéia, hipotensão e envolvimento de mucosa (Warnock e Morris, 2002). Tais sinais não foram encontrados neste caso.

O dano cutâneo possivelmente é mediado por linfócitos T citotóxicos e por células mononucleares que induzem à apoptose dos ceratinócitos, os quais apresentam antígenos derivados de drogas em suas superfícies (Fritsch e Sidoroff, 2000). O diagnóstico é realizado através da presença das lesões características, do estudo anatomopatológico compatível e da história clínica - fundamental para estabelecer o fator desencadeante (Petri, 2001).

Ao suspeitar-se de determinada droga, deve-se observar a relação temporal entre a introdução da medicação e o surgimento das lesões: aquelas introduzidas de sete até 21 dias antes do início do quadro provavelmente serão as responsáveis (Rasmussen, 2002). Entretanto, as introduzidas até dois meses podem ser as causadoras e devem ser imediatamente suspensas (Rasmussen, 2002). O dechallenge e o rechallenge, respectivamente, a parada da administração da droga suspeita e sua reintrodução, podem ser úteis para corroborar a associação da medicação em questão com o quadro cutâneo. Entretanto, dada à gravidade potencial da doença, a reintrodução da droga não deve ser realizada (Fritsch e Sidoroff, 2000).

O presente caso ilustra uma alteração dermatológica compatível com eritema multiforme (forma minor) associada ao uso da ziprasidona. Embora este diagnóstico tenha sido sugerido pela história e características clínicas das lesões apresentadas pela paciente, não foi possível a realização, em tempo hábil, de biópsia para confirmação anatomopatológica do diagnóstico.

Devido ao potencial de gravidade do eritema multiforme, a detecção precoce e a imediata suspensão da droga são fundamentais para redução da morbidade associada a esta afecção. Embora haja menção prévia a efeitos colaterais de natureza cutânea durante o uso de ziprasidona (Taylor et al., 2004; Warnock e Morris, 2002) não se encontrou na literatura relatos de associação entre eritema multiforme e esta medicação. 


\section{Referências bibliográficas}

Brett, A.S.; Philips, D.; LYNn, A.W. - Intravenous Immunoglobulin Therapy for Stevens-Johnson Syndrome. South Med J 94(3): 342-3, 2001.

Fritsch, P.O.; SidorofF, A. - Drug-Induced Stevens-Johnson Syndrome/Toxic Epidermal Necrolysis. Am J Clin Dermatol 1(6): 349-60, 2000.

Medical Economics. Physician's Desk Reference. $55^{\text {th }}$ ed. Montvale (NJ): Medical Economics, 2001.
Petri, V. - Eritema polimorfo e eritema nodoso. In: Prado, F.C.; Ramos, J.A. \& Valle, J.R. - Atualização terapêutica. $20^{\mathrm{a}}$ edição. Artes Médicas. São Paulo, pp.169, 2001.

RASMUSSEN, J.E. - Erythema Multiforme: a Practical Approach to Recent Advances. Pediatric Dermatolog; 19(1): 82-84, 2002. Taylor; Francis Group's Drug Eruption Global Database Online, 2004. Disponível em: URL: http://www.drugeruptiondata.com

WARNoCK, J.K.; MoRRIS, D.W. - Adverse Cutaneous Reactions to Antipsychotics. Am J Clin Dermato/3(9): 629-636, 2002. 